\title{
Effectiveness of counter traction using a clip with a looped thread for colorectal endoscopic submucosal dissection $\square$
}

\section{다(1) $(\Theta$}

\author{
Authors \\ Naohiko Indo $^{1,2}$, Takahiro Anami ${ }^{1}$, Yasuaki Kitamura ${ }^{1}$, Akihiko Watanabe $^{1}$ \\ Institutions \\ 1 Department of Gastroenterology, Yodogawa Christian \\ Hospital, Osaka, Japan \\ 2 Kohshinkai Gastroenterological Endoscopic Clinic, \\ Osaka, Japan \\ submitted 2.6.2020 \\ accepted after revision 11.11.2020 \\ Bibliography \\ Endoscopy International Open 2021; 09: E306-E312 \\ DOI 10.1055/a-1336-2460 \\ ISSN 2364-3722 \\ (c) 2021. The Author(s). \\ This is an open access article published by Thieme under the terms of the Creative \\ Commons Attribution-NonDerivative-NonCommercial License, permitting copying \\ and reproduction so long as the original work is given appropriate credit. Contents \\ may not be used for commecial purposes, or adapted, remixed, transformed or \\ built upon. (https://creativecommons.org/licenses/by-nc-nd/4.0/) \\ Georg Thieme Verlag KG, Rüdigerstraße 14, \\ 70469 Stuttgart, Germany \\ Corresponding author \\ Naohiko Indo, MD, 1-7-50 Kunijima, Higasi Yodogawa-ku, \\ Osaka, 533-0024, Japan \\ Fax: +81663206308 \\ inchan0701@gmail.com
}

\section{Introduction}

Colorectal cancer is the third most common type of cancer and the second most common cause of cancer-related mortality in the world [1]. Endoscopic resection of adenomatous polyps is reported to reduce the incidence of colorectal cancer [2]. However, polyps that are large and those that are removed piecemeal are risk factors for residual neoplasia [3]. Therefore, colorectal endoscopic submucosal dissection (ESD) has been found to have a high en bloc resection rate compared with endoscopic mucosal resection (EMR) [4]. In recent years, colorectal ESD has become a common endoscopic procedure. However, in Western countries, colorectal ESD is not the standard treatment for large colorectal lesions $[5,6]$ because the procedure is challenging and the rate of perforation is higher than that for EMR [7]. These challenges are attributable to the fact that the colorectal wall is thin and the maneuvering ability of the endoscope in the colon is limited. In addition, several factors pertaining to technical difficulties have been reported $[8,9]$. To ensure smooth and safe performance of colorectal ESD, it is important to maintain appropriate visibility of the submucosal layer in an easy and quick manner. Therefore, we developed a treatment strategy for colorectal ESD using a clip with a looped thread (LT) [10]. This traction method is cost-effective as well as easy to perform compared with previously reported methods. The present study was designed to evaluate the safety and effectiveness of this novel traction method.

\section{Patients and methods}

In June 2018, we introduced a counter traction method using a clip with a LT. We treated 120 consecutive colorectal lesions in 119 patients using ESD before and after the introduction of this traction method at the Yodogawa Christian Hospital between January 2017 and April 2019. ESD was indicated for lesions sized $>20 \mathrm{~mm}$ or for those sized $<20 \mathrm{~mm}$ that were expected to have fibrosis and were deemed difficult to resect en bloc with the snare. ESD was performed by four endoscopists who had performed at least 100 ESDs and 10 colorectal ESDs. According to the Japanese classification [11], laterally spreading tumors (LSTs) were classified into laterally spreading tumors granular type (LST-G) and laterally spreading tumors non-granular type (LST-NG). Polypoid lesions, such as type $0-\mathrm{I}$ of the Paris endoscopic classification [12], were also defined as elevated type.

A total of two lesions in two patients were excluded because of interrupting ESD. In one patient, ESD was interrupted due to acute exacerbation of chronic heart failure, and in the other patient, ESD was interrupted because of severe muscle retraction with submucosal invasion.

Total 68 lesions in 67 patients were treated before the introduction of the method and ESD was performed using various methods. Forty-two lesions were resected using conventional ESD; of these, seven located in the rectum or the sigmoid colon were resected using normal clip with line method, the same method used for ESD performed in esophageal cancer [13] (to 


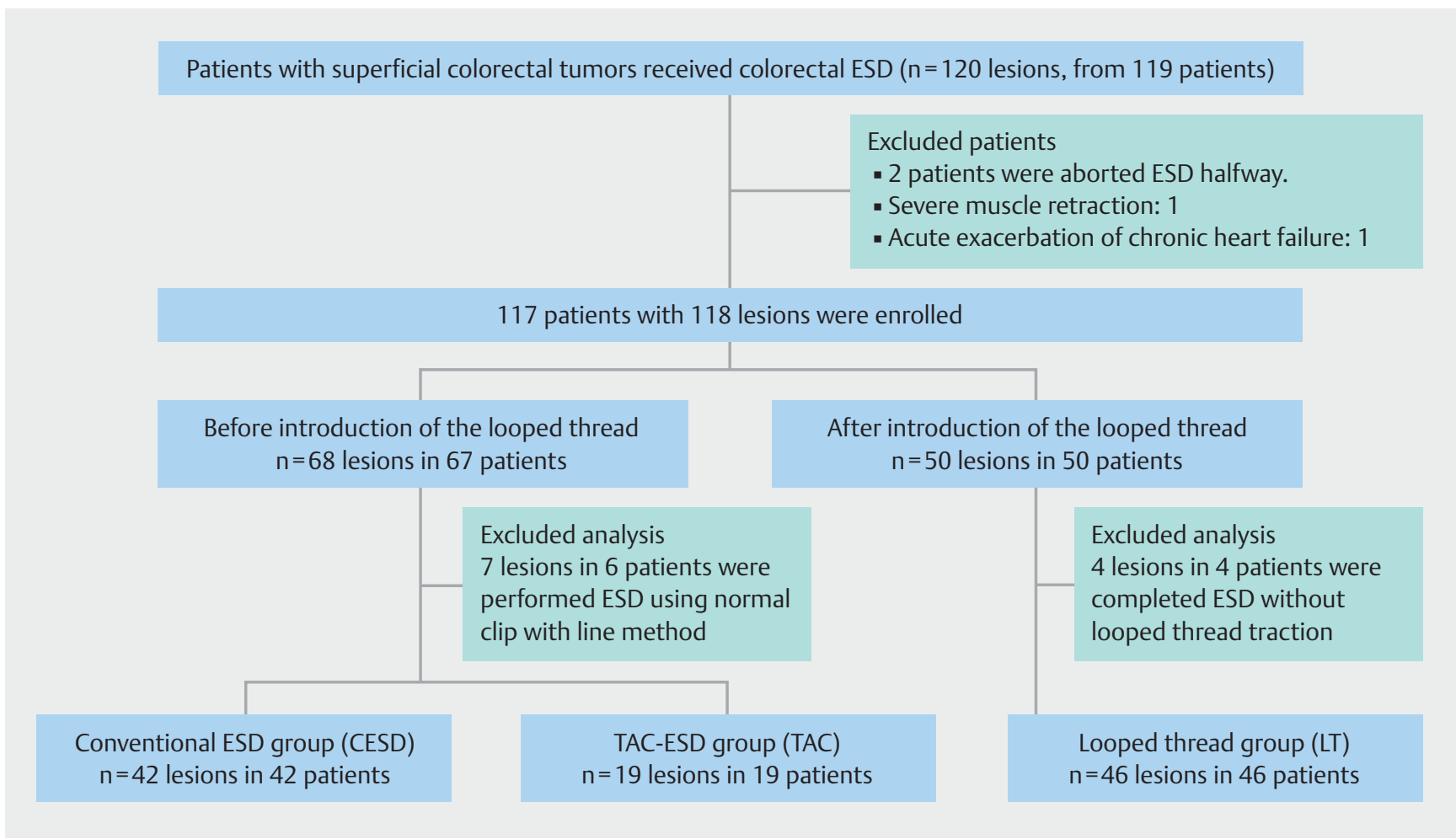

Fig. 1 Flowchart of the study.

set the clip and thread, the endoscope was withdrawn and reinserted), and 19 were resected using traction-assisted colorectal ESD (TAC-ESD) [14]. The 42 lesions resected using conventional ESD were allocated to the conventional ESD group (CESD group), and 19 lesions resected using TAC-ESD were allocated to the TAC group. Seven lesions except for these two groups were excluded from this study. The other 50 lesions in 50 patients who were treated after the introduction of the method were allocated to the LT group. In the LT group, ESD was performed for 46 lesions using the LT counter traction method. The four lesions were resected without LT traction because the good visibility of the submucosal layer could be maintained owing to gravity. Therefore, these four lesions were excluded. Finally, 107 lesions in 107 patients were analyzed in our study ( $\triangleright$ Fig. 1). To evaluate the effectiveness of the LT traction method, the CESD and TAC groups were separately compared with the LT group. The ethics committee of the Yodogawa Christian Hospital approved this study.

\section{Preparation and endoscopic system of colorectal ESD}

Colon pretreatment was performed using 0.15-L magnesium citrate on the night before the ESD and using 1.2 to 2-L low-volume polyethylene glycol solution (Moviprep, EA Pharma Co. Tokyo, Japan) on the day of ESD. When the stool became clear, coIon preparation was considered complete. If the stools were not clear after taking $2 \mathrm{~L}$ of low-volume polyethylene glycol solution, $120-\mathrm{mL}$ glycerine enema or isotonic magnesium citrate solution was used.
ESD was performed using a colonoscope with a waterjet instrument (PCF-H290, CF-HQ290 or PCF-H290T; Olympus, Tokyo, Japan) and an attachment (D-201-12704; Olympus) fitted to the tip. Incision and dissection were performed with a FlushKnife BTS (DK2620 J -B15S-; Fujifilm) or a DualKnife] (KD-655Q; Olympus, Tokyo, Japan). Precut-coagulation of vessel or hemostasis was performed with Coagrasper (FD-411QR; Olympus, Tokyo, Japan). In addition, hyaluronic acid (MucoUp; Boston scientific Tokyo, Japan) with a small volume of epinephrine and indigo carmine was injected.

High-frequency power supply (VIO300D; Erbe, Tübingen, Germany) was used. The endocut I mode (effect 3, duration 2, interval 2) was used for mucosal incision and submucosal dissection. The forced coagulation mode $45 \mathrm{~W}$ (effect 2) was used for submucosal dissection, and the soft coagulation mode $80 \mathrm{~W}$ (effect 5) was used for precut-coagulation and hemostatic treatment.

\section{Novel counter traction method using a clip with a looped thread}

The authors have previously reported this traction method [10]. First, a clip with a LT was prepared with a 3-0-nylon suture and a clip (HX-610-135; Olympus, Tokyo, Japan). Two loops were made with a 3-0-nylon suture. The first loop was made by looping and knotting a thread. The major axis of this loop was set between 5 and $10 \mathrm{~mm}$ because if it was too large, the counter traction would not be sufficient, and if it was too small, it would be difficult to place the second clip ( $\mathbf{F i g . 2 a ) . ~ T h e r e - ~}$ after, the second loop was made by looping and keeping it in 


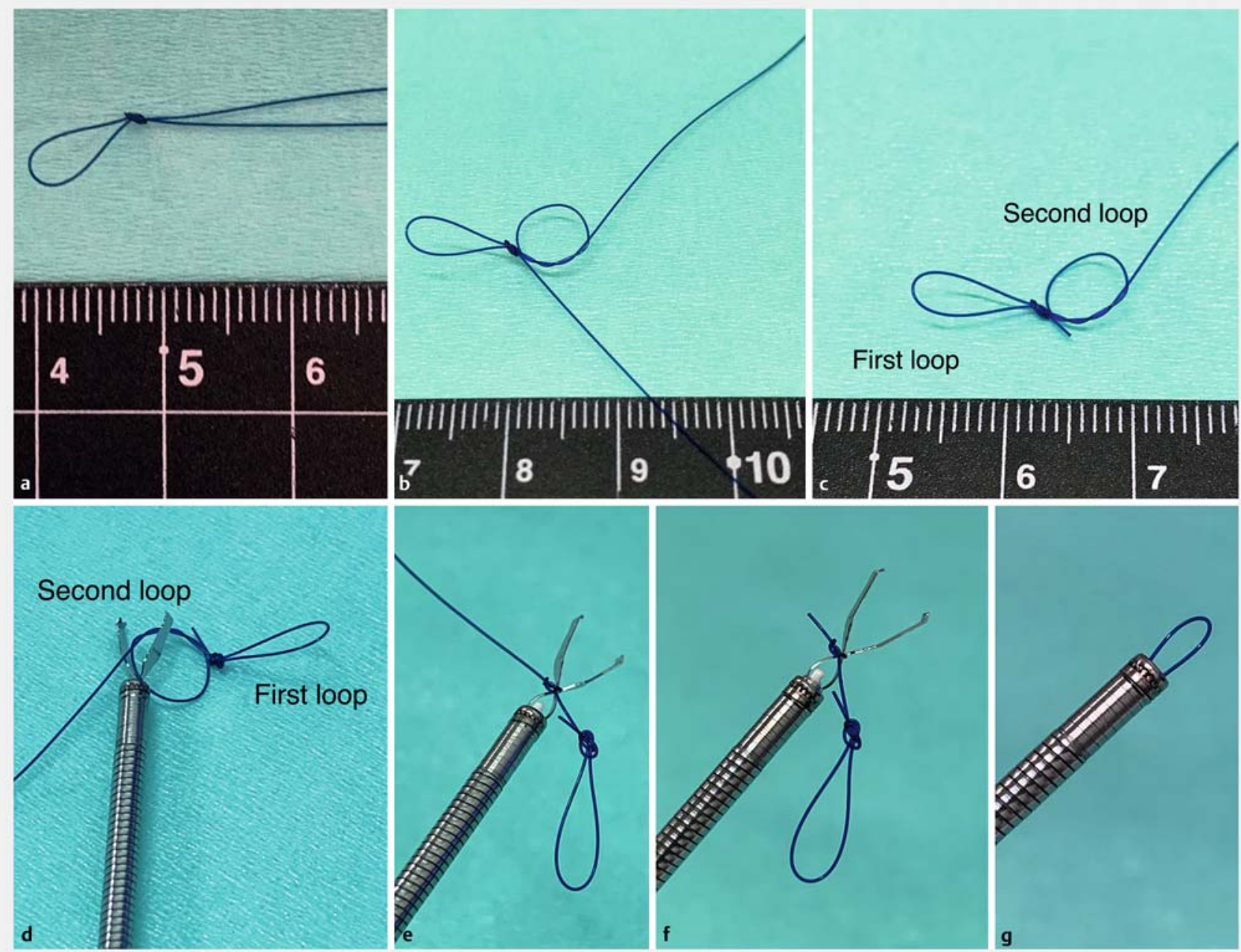

- Fig. 2 Clip with a looped thread. a The first loop is made by looping and knotting a 3-0 nylon suture. b The second loop is made by looping and keeping in the middle of ligature. $\mathbf{c}$ The unnecessary part of the thread is cut. $\mathbf{d}$ A clip is opened halfway. e The second loop of the thread is tied tightly to the arm part of the clip. $\mathbf{f}$ The unnecessary part of the thread is cut. $\mathbf{g}$ A completed clip with a looped thread.

the middle of ligature ( $\mathbf{F i g . 2 b}$ and $\boldsymbol{\nabla}$ Fig. $\mathbf{2 c}$ ). After making the LT, this second loop was tied to the arm part of the clip that was opened halfway ( $\triangleright$ Fig. 2 d and $\triangleright$ Fig. 2e). The key point is to tie the second loop tightly. Then, the unnecessary part of the thread was cut ( $\nabla$ Fig. $\mathbf{2 f}$ ). The procedure was completed by

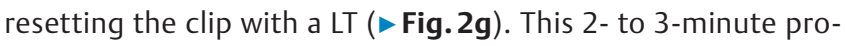
cess completed the preparation before ESD.

After preparation of a clip and a thread, ESD was performed ( $\triangleright$ Video 1). First, a mucosal circumferential incision was made ( $\vee$ Fig.3a and $\triangleright$ Fig.3b). Then, a clip with a LT that was prepared in advance was placed at the proximal end of the lesion ( $\mathbf{F i g . 3 c}$ ). Finally, a second new clip was placed on the contralateral side of the lesion with the other loop of the thread ( $\triangleright$ Fig.3d). By elevating the mucosa, the dissection of the remaining submucosal layer was performed ( $\triangleright$ Fig. 3e). After the completion of ESD, the loop of thread was cut using a loop cutter (FS-5Q-1; Olympus, Tokyo, Japan). The lesion was then recovered along with the first clip and thread [10]. If the loop cutter is not available due to institution reasons, the alternative is to grasp the clip on the normal mucosa side with a polypectomy snare and remove the clip with gentle traction.

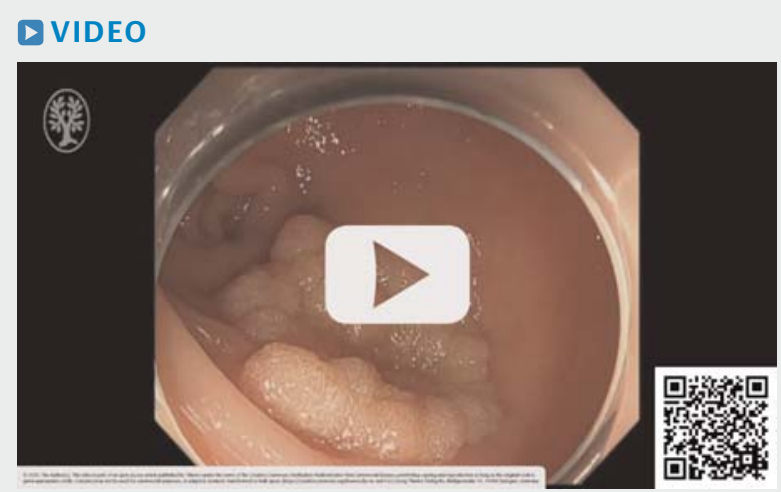

- Video 1 Colorectal ESD using a clip with a looped thread. 


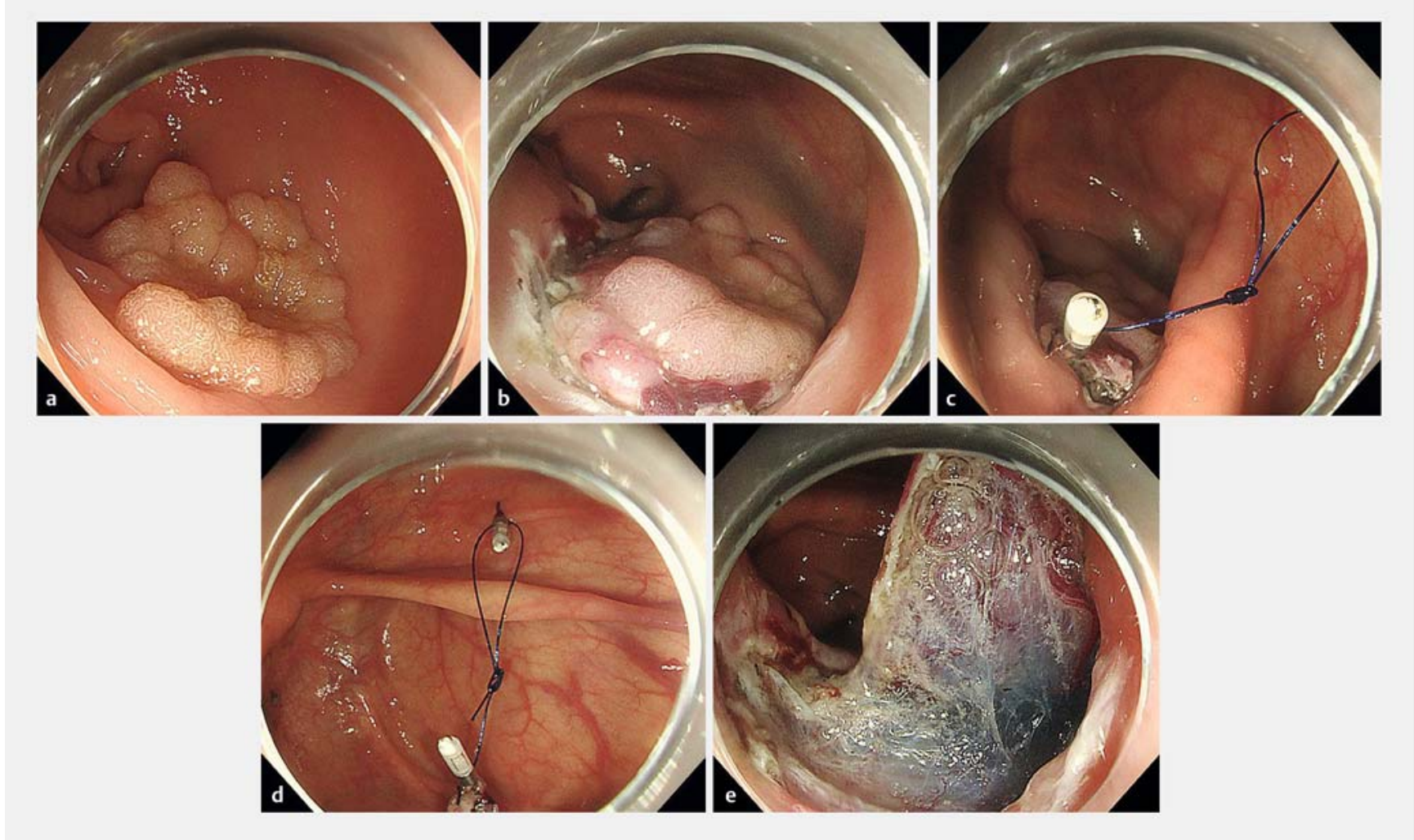

- Fig. 3 Colorectal ESD using a clip with a looped thread. a Granular laterally spreading tumor ( $25 \mathrm{~mm}$ in size) in the cecum. b Mucosal circumferential incision and submucosal dissection. c A first clip with a looped thread is placed at the proximal end of the lesion. $\mathbf{d}$ A second clip is placed on the contralateral side of the lesion. e Completion of the counter traction.

After resection, we evaluated the location of the lesions, findings of the macroscopic examination, histopathological findings, tumor diameter, approximate resected area, procedure time, and dissection speed per minute. Histopathological findings were classified according to the Japanese classification [11]. The shorter and longer axes were measured after ESD. Tumor diameter was defined as the longer axis. Procedure time was defined as the time from the initiation of mucosal incision to the end of dissection. The approximate resected area $\left(\mathrm{mm}^{2}\right)$ and dissection speed $\left(\mathrm{mm}^{2} / \mathrm{min}\right)$ were calculated by using the following formulas:

Approximate resected area $\left(\mathrm{mm}^{2}\right)=$ Major axis $(\mathrm{mm}) / 2 \times \mathrm{Mi}-$ nor axis $(\mathrm{mm}) / 2 \times 3.14$

Dissection speed $\left(\mathrm{mm}^{2} / \mathrm{min}\right)=$ resected area $\left(\mathrm{mm}^{2}\right) /$ procedure time ( $\mathrm{min}$ )

Procedure success rate and setting time of the counter traction using a clip with a LT were not evaluated because the new clip with the LT can be prepared in a few minutes and used in case of procedure failure.

\section{Endpoints}

The primary endpoint was dissection speed, and the secondary endpoints were procedure time; en bloc resection rate; and occurrence of adverse events, such as perforation during ESD and post-ESD bleeding that was defined as overt bleeding within 7 days after ESD procedure.

\section{Statistical analyses}

All the statistical analyses were performed with the EZR software (version 1.27, Saitama Medical Centre, Jichi Medical University, Saitama, Japan), a graphical user interface for $R$ (The $R$ Foundation for Statistical Computing, Vienna, Austria). [15] Categorical data were compared using Fisher's exact test or $x^{2}$ test. Continuous data were analyzed using $t$ test and MannWhitney U-test. $P<0.05$ was considered statistically significant.

\section{Results}

Baseline characteristics of the patients are shown in $>$ Table 1 . With respect to lesion location, in the TAC group, there were no lesions in the rectum because TAC-ESD is generally used for lesions in the cecum and colon. However, there was no significant difference between the TAC and LT groups. There were no significant differences in other factors between the CESD and LT groups and between the TAC and LT groups.

The treatment outcomes are shown in $\mathbf{r}$ Table 2 . For the CESD and LT groups or the TAC and LT groups, no significant differences were observed in tumor diameter and approximate resected area, respectively. Similarly, there was no significant difference in en bloc resection rate between the CESD and LT groups: $97.6 \%(41 / 42)$ vs. $100 \%(46 / 46 ; P=0.471)$ and between the TAC and LT groups: $94.7 \%$ (18/19) vs. $100 \%$ (46/46; 
- Table 1 Baseline characteristics of patients.

\begin{tabular}{|c|c|c|c|c|c|}
\hline & CESD group & TAC group & LT group & \multicolumn{2}{|l|}{$P$-value } \\
\hline & & & & CESD vs LT & TAC vs LT \\
\hline Age (median $\pm S D$ ) & $68 \pm 10$ & $69 \pm 10$ & $69 \pm 10$ & 0,487 & 0,462 \\
\hline Gender (male / female) & $27 / 15$ & $11 / 8$ & $25 / 21$ & 0,279 & 0,597 \\
\hline Location, n & & & & 0,461 & 0,128 \\
\hline - Cecum & $3(7.1 \%)$ & $1(5.3 \%)$ & $8(17.4 \%)$ & & \\
\hline - Colon & $29(69.1 \%)$ & $18(94.7 \%)$ & $33(71.7 \%)$ & & \\
\hline - Rectum & $10(23.8 \%)$ & 0 & $5(10.9 \%)$ & & \\
\hline Macroscopic findings, $n$ & & & & 0,557 & 0,865 \\
\hline - LST-G & $19(45.2 \%)$ & $11(57.9 \%)$ & $17(37 \%)$ & & \\
\hline - LST-NG & $16(38.1 \%)$ & $6(31.6 \%)$ & $13(28.2 \%)$ & & \\
\hline - Elevated lesion & $7(16.7 \%)$ & $2(10.5 \%)$ & $16(34.8 \%)$ & & \\
\hline
\end{tabular}

- Table 2 Treatment outcomes and adverse events.

\begin{tabular}{|c|c|c|c|c|c|}
\hline & CESD group & TAC group & LT group & \multicolumn{2}{|l|}{$P$-value } \\
\hline & & & & CESD vs LT & TAC vs LT \\
\hline En bloc resection, $\mathrm{n}$ & $41(97.6 \%)$ & $18(94.7 \%)$ & $46(100 \%)$ & 0,471 & 0,292 \\
\hline $\begin{array}{l}\text { Tumor diameter, median } \\
\text { (range), mm }\end{array}$ & $25(16-50)$ & $27(15-38)$ & $25(12-85)$ & 0,685 & 0,994 \\
\hline $\begin{array}{l}\text { Approximate resected area, } \\
\text { median (range), } \mathrm{mm}^{2}\end{array}$ & $706.5(226-3886)$ & $730(353-2524.5)$ & $753.6(235.5-6539)$ & 0,135 & 0,942 \\
\hline $\begin{array}{l}\text { Procedure time, median } \\
\text { (range), min }\end{array}$ & $65(15-285)$ & $90(40-240)$ & $59.5(20-240)$ & 0,446 & 0,006 \\
\hline $\begin{array}{l}\text { Dissection speed, median } \\
\text { (range), } \mathrm{mm}^{2} / \mathrm{min}\end{array}$ & $9.15(3.01-39.26)$ & $9.61(2.21-28.05)$ & $14.46(4.18-83.02)$ & 0,035 & 0,051 \\
\hline Perforation during ESD, $n$ & $2(4.8 \%)$ & $1(5.2 \%)$ & $1(2.2 \%)$ & 0,501 & 0,862 \\
\hline Post ESD bleeding, $\mathrm{n}$ & $3(7.1 \%)$ & $1(5.2 \%)$ & $3(6.5 \%)$ & 0,892 & 0,531 \\
\hline Pathological findings, $\mathrm{n}$ & & & & 0,884 & 0,548 \\
\hline - adenoma & $19(45.2 \%)$ & $7(36.8 \%)$ & $21(45.7 \%)$ & & \\
\hline - Intramucosal carcinoma & $14(33.3 \%)$ & $7(36.8 \%)$ & $16(34.8 \%)$ & & \\
\hline $\begin{array}{l}\text { - Submucosal carcinoma } \\
(<1000 \mu \mathrm{m})\end{array}$ & $3(7.1 \%)$ & $2(10.5 \%)$ & $3(6.5 \%)$ & & \\
\hline $\begin{array}{l}\text { - Submucosal carcinoma } \\
(>1000 \mu \mathrm{m})\end{array}$ & $1(2.4 \%)$ & $1(5.3 \%)$ & $2(4.3 \%)$ & & \\
\hline . SSA/P & $5(11.9 \%)$ & $2(10.5 \%)$ & $4(8.7 \%)$ & & \\
\hline
\end{tabular}


$P=0.292)$. The procedure time in the CESD and LT groups was not significantly different at 65.0 minutes $(15-285 \mathrm{~min})$ vs. $59.5 \mathrm{~min}(20-240 \mathrm{~min} ; P=0.446)$; conversely, there was a significant difference between the TAC and LT groups at $90.0 \mathrm{~min}$ (40-240 min) vs. $59.5 \mathrm{~min}(20-240 \mathrm{~min} ; P=0.006)$. The dissection speed in the CESD and LT groups was significantly different at $9.15 \mathrm{~mm}^{2} / \mathrm{min}\left(3.01-39.26 \mathrm{~mm}^{2} / \mathrm{min}\right)$ vs. $14.46 \mathrm{~mm}^{2} /$ $\min \left(4.18-83.02 \mathrm{~mm}^{2} / \mathrm{min} ; P=0.035\right)$, alternatively, there was no significant difference between the TAC and LT groups at $9.61 \mathrm{~mm}^{2} / \mathrm{min} \quad\left(2.21-28.05 \mathrm{~mm}^{2} / \mathrm{min}\right) \quad$ vs. $\quad 14.46 \mathrm{~mm}^{2} / \mathrm{min}$ (4.18-83.02 $\left.\mathrm{mm}^{2} / \mathrm{min} ; P=0.051\right)$. Perforation during ESD occurred in two patients (4.8\%) in the CESD group, in one patient $(5.2 \%)$ in the TAC group and in one patient $(2.2 \%)$ in the LT group. Post-ESD bleeding occurred in three patients (7.1\%) in the CESD group, in one patient (5.2\%) in the TAC group and in three patients $(6.5 \%)$ in the LT group. There were no significant differences in perforation and bleeding between CESD and LT groups or between the TAC and LT groups. All patients in whom perforations and bleeding were observed were successfully treated with endoscopy. The perforation sites were closed with a clip during the procedures. Hemostasis was performed with clip or forceps; thus, emergency operation could be avoided.

\section{Discussion}

Colorectal ESD enables the performance of en bloc and curative resection of large colorectal lesions for which en bloc resection with EMR is challenging [4]. Nevertheless, it is uncommon in regions other than East Asia because the procedure is technically challenging and has a high incidence rate of adverse events and a long procedure time $[5,6,8,9]$. Therefore, safety and shorter procedure time are important factors that would increase the use of ESD worldwide. In esophageal or gastric ESD, the use of a clip with the line method is very useful. Furthermore, some studies have reported a significant reduction in the dissection time compared with that in conventional ESD, especially in esophageal ESD. [16-18] However, it is necessary to remove and reinsert the endoscope to attach the clip with the line. Therefore, it is difficult to use for colorectal ESD, except in rectal or sigmoid lesions. Hence, several traction methods have been reported to date, including S-O clip, [19] TAC-ESD, [14] pocket creation method, [20] cross-counter technique, [21] clip-and-snare method, [22] clip flap method [23], and ringshaped thread counter traction [24]. However, these methods have some problems concerning preparation, delivery, simplicity, and cost. Factors that are important to ensure widespread use of the counter traction method are not only effectiveness but also simplicity and low cost. Among these traction methods, the ring-shaped thread counter traction method is easy, inexpensive, and simple. However, placement of the clip and ring-shaped thread on the lesion is slightly difficult, time-consuming, and tedious because the ring-shaped thread is carried to the lesion using forceps before the clip. Therefore, we recommend use of our counter traction method using a clip with a LT. The concept of the ring-shaped counter traction method and that of our traction method are the same. The difference is in the delivery of the thread. In our traction method, the LT is tied to the clip beforehand. Thus, the clip and the thread can be placed more easily and more quickly than the ring-shaped thread in the counter traction method. Moreover, the counter traction strategy using a double clip and rubber band [25] that was reported in 2018 employs the same concept as our traction method. However, because of the extensibility of the lesion, a thread can be used instead of a rubber band for adequate traction. Furthermore, traction intensity can be adjusted by air supply from the endoscope. Using a thread, after the completion of dissection, the thread can be cut easily using a loop cutter. Therefore, the lesions can be retrieved without damaging them. In addition, the LT traction method does not require repositionable clips, and regular clips are used. This makes it more cost-effective. It is assumed that these are the advantages of our traction method.

The advantages of our traction method can be summarized as follows. First, the only materials that are needed are a clip and a nylon suture, which are inexpensive and can be easily prepared. Second, the procedure can be performed without withdrawal and reinsertion of an endoscope in contrast to that for the standard clip with line method. Third, the direction and strength of traction can be adjusted by changing the size of the loop and the position of the second clip, depending on the site of the lesion and the progress of the dissection, unlike methods such as the S-O clip, TAC-ESD or standard clip with line method, which can only be pulled toward a specific direction. Finally, if the first clip and LT is insufficient or fails, more clips or LTs can be easily added. Therefore, this traction method is readily available not only in high volume centers but also in general hospitals.

We can get stable visibility of the submucosal layer and recognize the dissection line; thus, an increase in dissection speed and a reduction in procedure time can be expected. Regarding adverse events, although there were no significant differences in perforation during ESD and bleeding after ESD, this traction method is expected to prevent perforation and bleeding during the ESD procedure. The muscle layer and blood vessels can be recognized clearly by elevating the mucosa. This matter requires further consideration.

This study showed the effectiveness of this traction method but there are certain limitations. First, this study was retrospective study and conducted at a single center. Second, there was a learning curve with this method. Because there are not many cases of colorectal ESD at our institution, it was difficult to ensure sufficient experience of all endoscopists at the start of this study. In this study, we evaluated this traction method before and after its introduction. Therefore, the LT method was applied during the latter period of the entire study period. The possibility that the learning curve was affected could not be excluded.

Apart from the limitations of this study, there is one thing to be aware of when using this traction method. Although the method is generally effective for LST lesions, it is important to understand that some elevated lesions may not benefit from it. In large, elevated lesions that have large nodules, the muscle layer is sometimes pulled toward a neoplastic tumor. In those 
cases, not only is counter-traction ineffective, but ESD may be difficult to complete.

\section{Conclusion}

In conclusion, this counter traction method has the potential to be one of the most useful traction methods for colorectal ESD because it addresses the limitations of previously reported methods. Further prospective multicenter studies are required to elucidate the efficacy of this method more precisely.

\section{Acknowledgements}

The authors thank A. Nishio for technical support, S. Miura for technical assistance, and Enago (www.enago.jp) for English language review.

\section{Competing interests}

The authors declare that they have no conflict of interest.

\section{References}

[1] Bray F, Ferlay J, Soerjomataram I et al. Global cancer statistics 2018: GLOBOCAN estimates of incidence and mortality worldwide for 36 cancers in 185 countries. CA Cancer J Clin 2018; 68: 394-424

[2] Zauber AG, Winawer SJ, O'Brien M] et al. Colonoscopic polypectomy and long-term prevention of colorectal-cancer deaths. N Engl J Med 2012; 366: 687-696

[3] Woodward TA, Heckman MG, Cleveland P et al. Predictors of complete endoscopic mucosal resection of flat and depressed gastrointestinal neoplasia of the colon. Am J Gastroenterol 2012; 107: 650654

[4] Saito Y, Fukuzawa M, Matsuda T et al. Clinical outcome of endoscopic submucosal dissection versus endoscopic mucosal resection of large colorectal tumors as determined by curative resection. Surg Endosc 2010; 24: 343-352

[5] Shinozaki S, Hayashi Y, Lefor AK et al. What is the best therapeutic strategy for colonoscopy of colorectal neoplasia? Future perspectives from the East Dig Endosc 2016; 28: 289-295

[6] Burgess NG, Bourke M]. Endoscopic resection of colorectal lesions: The narrowing divide between East and West. Dig Endosc 2016; 28: 296-305

[7] Arezzo A, Passera R, Marchese $N$ et al. Systematic review and meta-analysis of endoscopic submucosal dissection vs endoscopic mucosal resection for colorectal lesions. United Eur Gastroenterol J 2016; 4: $18-29$

[8] Hori K, Uraoka T, Harada K et al. Predictive factors for technically difficult endoscopic submucosal dissection in the colorectum. Endoscopy 2014; 46: 862-870
[9] Takeuchi Y, lishi H, Tanaka S et al. Factors associated with technical difficulties and adverse events of colorectal endoscopic submucosal dissection: retrospective exploratory factor analysis of a multicenter prospective cohort. Int J Colorectal Dis 2014; 29: 1275-1284

[10] Indo N, Anami T, Asaji N et al. Easy and effective counter-traction using a clip with a looped thread for colorectal endoscopic submucosal dissection. Endoscopy 2019; 51: E233-E234

[11] Japanese Society for Cancer of the Colon and Rectum. Japanese Classification of Colorectal, Appendiceal, and Anal Carcinoma 3rd ed. J Anus Rectum Colon 2019; 3: 175-195

[12] Participants in the Paris Workshop. The Paris endoscopic classification of superficial neoplastic lesions: esophagus, stomach, and colon. Gastrointest Endosc 2003; 58: S3-S43

[13] Oyama T, Shimaya S, Tomori A et al. Endoscopic mucosal resection using a hooking knife (hooking EMR). Stomach Intest 2002; 37: 11551161

[14] Yamasaki $\mathrm{Y}$, Takeuchi $\mathrm{Y}$, Uedo $\mathrm{N}$ et al. Traction-assisted colonic endoscopic submucosal dissection using clip and line: a feasibility study. Endosc Int Open 2015; 04: E51-E55

[15] Kanda Y. Investigation of the freely available easy-to-use software "EZR" for medical statistics. Bone Marrow Transplant 2013; 48: 452458

[16] Ota M, Nakamura T, Hayashi K et al. Usefulness of clip traction in the early phase of esophageal endoscopic submucosal dissection. Dig Endosc 2012; 24: 315-318

[17] Koike $Y$, Hirasawa D, Fujita $N$ et al. Usefulness of the thread-traction method in esophageal endoscopic submucosal dissection: randomized controlled trial. Dig Endosc 2015; 27: 303-309

[18] Xie X, Bai JY, Fan CQ et al. Application of clip traction in endoscopic submucosal dissection to the treatment of early esophageal carcinoma and precancerous lesions. Surg Endosc 2017; 31: 462-468

[19] Sakamoto N, Osada T, Shibuya T et al. Endoscopic submucosal dissection of large colorectal tumors by using a novel spring-action S-O clip for traction (with video). Gastrointest Endosc 2009; 69: 13701374

[20] Sakamoto H, Hayashi Y, Miura Y et al. Pocket-creation method facilitates endoscopic submucosal dissection of colorectal laterally spreading tumors, non-granular type. Endosc Int Open 2017; 05: E123-E129

[21] Okamoto K, Muguruma N, Kitamura S et al. Endoscopic submucosal dissection for large colorectal tumors using a cross-counter technique and a novel large-diameter balloon overtube. Dig Endosc 2012; 24: $96-99$

[22] Yamada S, Doyama H, Ota R et al. Impact of the clip and snare method using the prelooping technique for colorectal endoscopic submucosal dissection. Endoscopy 2016; 48: 281-385

[23] Yamamoto K, Hayashi S, Saiki H et al. Endoscopic submucosal dissection for large superficial colorectal tumors using the clip-flap method. Endoscopy 2015; 47: 262-265

[24] Mori H, Kobara H, Nishiyama $\mathrm{N}$ et al. Novel effective and repeatedly available ring-thread counter traction for safer colorectal endoscopic submucosal dissection. Surg Endosc 2017; 31: 3040-3047

[25] Jacques ], Charissoux A, Legros R et al. Double-clip counter-traction using a rubber band is a useful and adaptive tool for colonic endoscopic submucosal dissection. Endoscopy 2018; 50: 179-181 